\title{
Social PR campaign in promoting sustainable education within urban environment
}

\author{
Polina Sergienko ${ }^{1 *}$, Alla Minyar-Beloroucheva ${ }^{2}$, Olga Vishnyakova $^{3}$, and Elizaveta \\ Vishnyakova $^{4}$ \\ ${ }^{1}$ Lomonosov Moscow State University, Faculty of Foreign Languages and Area Studies, Department \\ of English for Humanities Faculties, Moscow, Russia \\ ${ }^{2}$ Lomonosov Moscow State University, History Faculty, Department of Foreign Languages, Moscow, \\ Russia \\ ${ }^{3}$ Lomonosov Moscow State University, Philological Faculty, Department of English Linguistics, \\ Moscow, Russia \\ ${ }^{4}$ Leo Tolstoy Tula State Pedagogical University, Faculty of Foreign Languages, Department of the \\ English Language, Tula, Russia
}

\begin{abstract}
The article reveals social PR campaign particularities aimed at raising awareness of the citizens in the urban environment. For the first time PR campaigns dealing with the urban environment decoration devoted to commemorative events, environmental protection measures, and social issues are investigated from the position of education for sustainable development. The urban area implies the encouragement of refashioned, renovated, changed, restructured and reconstructed environments necessary for edutainment of the citizens. It means that the analysis of the urban area focuses on the study of themes dealing with history, art, urgent domestic social issues and the problems of the natural environment. Education for Sustainable Development (ESD) is a perfect opportunity to give knowledge in the 'soft' way to the citizens, in addition to traditional 'hard' education within the urban environment. The methods used during the work on the article are comprehensive. They include observation, analysis, synthesis, description and interview. As a result of the study of the stated issues, the following conclusion was made. Urban area is an ideal platform to arouse the interest of its citizens by means of the thematic adornment of the city that expands their knowledge, makes them more persuasive and thus fosters the improvement of their behaviour. Information perceived laterally is better remembered and stored longer in memory. The citizens become more susceptible to any information offered to them by the officials of the city.
\end{abstract}

Keywords: social PR, urban environment.

\section{Introduction}

There is no unique definition of PR and the attitude of specialists is ambiguous. Some scholars think of PR as a benevolent practice, essential for society helping people to be

* Corresponding author: poserg@bk.ru 
conversant in this complicated world. One of the most successful definitions suggested by Dr. Rex Harlow in 1976 summarizes various prior attempts to define the subject matter:

"Public relations is a distinctive management function, which helps establish and maintain mutual lines of communication, understanding, acceptance and cooperation between an organization and its publics; involves the management of problems or issues; helps management to keep informed on and responsive to public opinion; defines and emphasized the responsibility of management to serve the public interest; helps management keep abreast of and effectively utilize change, serving as an early warning system to help anticipate trends; and uses research and sound ethical communication as its principal tools" [1].

Others are cautious and express their awareness that well planned communication could mislead the people. Prominent linguist Professor Noam Chomsky puts people on their guard regarding PR campaigns. In particular, he writes, criticizing the PR practice that it has been used 'to further the ends of a few, regardless of the needs of the many' [2]. This debate is a concern of separate investigations within the domain of ethical issues.

\subsection{Hypothesis of the study}

Urban environment is an ideal educational platform for sustainable development of the citizens as they constantly get information laterally that enrich their knowledge and are beneficial for their behavior.

\subsection{The purpose of the study}

The aim of the research is to reveal what kind of urban environment information arises curiosity on the part of the citizens, makes them enrich their knowledge on certain topics. The practical outcome of the urban area sustainable development is fostering the change of the citizens' behavior.

\section{Methods and methodology}

The methods applied during the present investigation are the following. The method of observation gives the information about the state of art. The method of interview enables to find out what topics have aroused the most interest, have been more persuasive to foster the improvement of behavior. Moreover, the methods of analysis and synthesis as well classification were used to develop understanding of the described phenomenon.

\section{Sustainable education}

Sustainable Education or Education for Sustainable Development (ESD) was the initiative of UN put forward at the Conference on Human Environment in Stockholm in 1972 [3] to help people meet the challenges of the time that makes it possible to use soft education and edutainment $[4,5]$ in the interests of society. The new approach to the surroundings needs fundamental changes that should be carried out in knowledge, skills, values and attitudes to live in a democratic society of the present. Education for Sustainable Development is defined in different ways. One of them runs as follows: "interdisciplinary learning methodology covering the integrated social, economic, and environmental aspects of formal and informal curriculum" [6]. The definition presupposes that education for sustainable development requires consistent implementation of different mechanisms to get knowledge in the interminably evolving world. As for the methods applied by the ESD, the adamants of this 
approach make use of such methods of teaching and education as stimulation, encouragement and inspiration to modify the people's behavior and urge actions. ESD proved to be effective as it develops competences such as critical thinking, decision making, creativity and collaborative actions.

\section{Results}

The investigation has found the presented examples of Social PR campaign conducted in the City of Moscow since 2007 effective. Real life examples of thematic trains of Moscow metro system include the following:

- During the Moscow social PR campaign that started in 2007 first with art and later for commemorative events in the Russian History, metro trains were given new names and appearances. The carriages inside were dedicated to the history and art of Russia. This practice can also be regarded as complimentary to traditional education on history and politics [7] as well as innovative practices [8].

- Some other social PR campaigns were devoted to the flora and fauna of the Far East. The train was launched in 2015 to increase awareness of the issue to protect endangered species and the importance of biodiversity. The entire space of the carriages, including the floors, was covered with images of rare animals and plants.

- the 2007-2020 Moscow metro trains became itinerary exhibitions where the pictures of the great artists of the past and present were on display. The exhibition is periodically updated. A train has been running with the updated exhibition featuring the pictures by Kustodiev, Shishkin, Repin and other famous artists.

The best lateral approach to promote sustainable education softly is the metro trains. The study has revealed two different types of urban environment education for sustainable development intended for common citizens: cultural-historical and social-health care information. This can also be regarded as creative environment [9] which stimulates reading and harmonizes different cognitive style learning strategies [10], as visual and verbal elements are involved. This type of sustainable education is to be regarded as edutainment, as people learn without special effort feeling involved. Such forms of education make the distinction between the game and education irrelevant.

A public opinion poll was conducted among 200 residents of Moscow to find out which topic of metro trains was most useful and expanded their knowledge. A question was asked: Which topic of the thematic trains did you like most? Four options were give: History, Art, Social Themes and the Environment. The results are presented in Figure 1, a pie chart indicating the percentage of the preferences expressed by the citizens.

\section{Thematic train preferences}

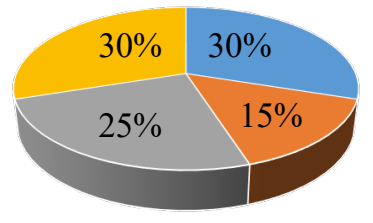

- History $\quad$ Art $\quad$ Social Themes $\Perp$ Environmental issues

Fig. 1. Pie Chart indicating thematic train preferences. 


\section{Discussion}

\subsection{Functions of PR campaigns}

There are various PR campaigns set with different objectives, having a common goal to promote interests of a certain side. Social PR campaigns are meant for the good of the people, serving the 'soul' marketing and PR campaigns [11], set for the cause to educate the urban population and increase the level of its culture. Benevolent actions of business companies, often revealed through CSR - corporate social responsibility as well as governmental programmes are aimed at targeting masses to make them more knowledgeable in history, culture and recently in medical safety. PR companies conduct their campaigns persistently being specific goal oriented. It should be stressed that no goal can be achieved without proper strategic plan and tactical implementations.

Theorists of PR campaigns [12, 13] worked out a successful classification of general objectives of campaigns. The first objective, singled out by the researchers, is mere information of the general public, or the creation of awareness. This may include information about an event or cause, as the date and venues for the local elections, or a city holiday taking place. This is bound to create awareness of the upcoming elections or a new event to be organized. Additionally, PR tailors might want to persuade the audience. This persuasion is usually aimed at changing the public's opinions and attitudes, as in social campaigns persuading people of the necessity to help those in need. The same objective can be pursued when framing Corporate Social Responsibility (CSR) campaign as an interplay between the communicator (corporate PR) the media and the public [14].

Another objective can be to urge the audience to behave in a certain way, as for example, to participate in elections or to take actions against a pandemic threat (e.g. the 'stayhome movement'). Finally, in the vision of the researchers the aim of a PR campaign can be manifested in education. Thus, in times when it is needed, medical information is provided to help educating the mass audience about the potential threat of viruses, or some lessons of history are latently taught to the younger generation by means of billboards and information leaflets distributed within the urban environment. Some authors put forward an idea that a good PR campaign is to include several objectives - in inform, to create awareness, to persuade, to urge publics and to educate the people [2].

\subsection{Urban Environment as a field of sustainable education and a social PR tool}

The term "Urban environment" originates from the analysis of the pictures and drawings combining social sciences and nature. According to researchers, its main area of application is society due to correlation with the population and social interaction. It is connected with the core of the living space organization [15], including small villages and big metropolises. Scientists traditionally view the development of various urban education facilities as a contributing factor for the civilization [16]. The study of the urban environment involves the ever-changing and modified environments [17], which can be seen as a set of social factors [18], enforced with natural sciences research. The present research is set to show the capacity of the urban environment used for sustainable education purposes and social PR actions. Transportation, garden ecology, architecture and urban planning traditionally studied in terms of urban development, get a new meaning in accord with education purposes. The urban environment can thus be considered from the angle of social relations, human activities and different social issues, including raising awareness within Social PR campaign and sustainable education.

PR campaign are always topically oriented and correspond to the commemorative dates. The metro carriages became the historical locomotives in the urban space. Within a short 
timespan of the trip it is impossible to read and learn all the information, thus it serves as a trigger to raise curiosity and make the people turn to the books to find out more about the events or the people whose images were presented in the social PR campaign. Commuters being exposed more frequently to this lateral information retain it longer in their minds.

\section{Conclusion}

Finishing off it should be said that human mind is always in the state of the never-ending inquisitiveness. It was appreciated by the UN members, who recognized and verbalized the necessity of life-long education for the people, which is presented in information acquisition. The whole urban environment becomes the medium for sustainable development. In this regard, the age of the person loses its relevance. People of all ages will clearly see mural paintings, benches and bus stops. The human brain is limitless and its cognitive abilities do not depend on the age. An inquisitive human mind is capable of learning every minute or even second, as it never loses its zest for knowledge. The information is also aimed at changing attitudes and shaping behavior of the target audience. The fast change of thematic issues meets the demand of the modern society, which is always in the state of a flux.

The practice of using metro train carriages for educating purposes, including raising public awareness social and health issues as well as general information on Art and History proves to be a soft skill measure to educate the citizens to improve their behavior. In terms of PR terms, these actions are regarded as social PR campaign for educational purposes.

\section{References}

1. S. Black, An Introduction to Public Relation (Modino Press, London, 1989)

2. S. Wolstenholme (Ed.), Introduction to Public Relation (Pearson Education Limited, Harlow, 2013)

3. United Nations, Report of the UN Conference on the Human Environment, Sustainable Development Knowledge Platform, 5-16 June 1972, Stockholm, Sweden (United Nations Publication, Stockholm, 1972). Accessed on: September 20, 2020. [Online]. Available:

https://www.un.org/ga/search/view_doc.asp?symbol=A/CONF.48/14/REV.1

4. M. Rey-López, A.F. Vilas, R.P.D. Redondo, A Model for Personalized Learning Through IDTV, in Adaptive Hypermedia and Adaptive Web-Based Systems. AH 2006. Lecture Notes in Computer Science, vol. 4018, 457-461 (Springer, Berlin, Heidelberg, 2006). https://doi.org/10.1007/11768012_69

5. M.K. Elteir, Sh. Lazem, M. Azab, Journal of King Saud University - Computer and Information Sciences (to be published). https://doi.org/10.1016/j.jksuci.2020.02.001

6. UNESCO, Educational for Sustainable Development (2013). Accessed on: May 24, 2020. [Online]. Available: https://en.unesco.org/themes/education-sustainabledevelopment

7. A. Minyar-Beloroucheva, P. Sergienko, O. Vishnyakova, E. Vishnyakova, Modern technologies in teaching professionally oriented foreign language to the students of politics, in ICERI2018 Proceedings of the $11^{\text {th }}$ Annual International Conference of Education, Research and Innovation, 12-14 November 2018, Seville, Spain, 79677975 (2018). https://doi.org/10.21125/iceri.2018.0043

8. W. Nancy, A. Parimala, L.M.M. Livingston, Procedia Computer Science, 172, 382388 (2020). https://doi.org/10.1016/j.procs.2020.05.059 
9. A. Minyar-Beloroucheva, P. Sergienko, E. Vishnyakova, O. Vishnyakova, International Journal of English Linguistics, 10(1), 26-36 (2020). https://doi.org/10.5539/ijel.v10n1p26

10. O. Vishnyakova, A. Minyar-Beloroucheva, P. Sergienko, E. Vishnyakova, Harmonizing different cognitive styles through reading, in 5th International eConference on Studies in Humanities and Social Sciences: Conference Proceedings, 24-28 June 2020, Belgrade, Serbia, 17-30 (2020). http://dx.doi.org/10.32591/coas.econf. $05.02017 \mathrm{v}$

11. T. Antric, D. McKie, M. Toledano, Public Relations Review, 45(5), 101827 (2019). https://doi.org/10.1016/j.pubrev.2019.101827

12. R.S. Rensburg (Ed.), Introduction to Communication: Communication Planning and Management (Juta, Cape Town, 1996)

13. R.S. Rensburg, M. Cant, Public Relations: African Perspectives (Heinemann, Sandton, 2009)

14. L. van den Heijkant, P. Vliegenthart, Public Relations Review, 44(5), 645-655 (2018). https://doi.org/10.1016/j.pubrev.2018.05.007

15. M. Lussault, Urbain, in Dictionnaire de la géographie et de l'espace des sociétés, 949951 (Belin, Paris, 2003)

16. F.A. Nuzir, B.J. Dewancker, Procedia Environmental Sciences, 20, 632-641 (2014) https://doi.org/10.1016/j.proenv.2014.03.076

17. J. Fu, G. Xiao, C. Wu, Journal of Cleaner Production, 273, 122551 (2020). https://doi.org/10.1016/j.jclepro.2020.122551

18. W.E. Cronon, Uncommon Ground: Rethinking the Human Place in Nature (W.W. Norton \& company, New York, 1996) 